\title{
Increased forefoot loading is associated with an increased plantar flexion moment
}

Citation for published version (APA):

Melai, T., Schaper, N. C., ljzerman, T. H., de Lange, T. L., Willems, P. J., Meijer, K., Lieverse, A. G., \& Savelberg, H. H. (2013). Increased forefoot loading is associated with an increased plantar flexion moment. Human Movement Science, 32(4), 785-793. https://doi.org/10.1016/j.humov.2013.05.001

Document status and date:

Published: 01/08/2013

DOI:

10.1016/j.humov.2013.05.001

Document Version:

Publisher's PDF, also known as Version of record

Document license:

Taverne

Please check the document version of this publication:

- A submitted manuscript is the version of the article upon submission and before peer-review. There can be important differences between the submitted version and the official published version of record.

People interested in the research are advised to contact the author for the final version of the publication, or visit the DOI to the publisher's website.

- The final author version and the galley proof are versions of the publication after peer review.

- The final published version features the final layout of the paper including the volume, issue and page numbers.

Link to publication

\footnotetext{
General rights rights.

- You may freely distribute the URL identifying the publication in the public portal. please follow below link for the End User Agreement:

www.umlib.nl/taverne-license

Take down policy

If you believe that this document breaches copyright please contact us at:

repository@maastrichtuniversity.nl

providing details and we will investigate your claim.
}

Copyright and moral rights for the publications made accessible in the public portal are retained by the authors and/or other copyright owners and it is a condition of accessing publications that users recognise and abide by the legal requirements associated with these

- Users may download and print one copy of any publication from the public portal for the purpose of private study or research.

- You may not further distribute the material or use it for any profit-making activity or commercial gain

If the publication is distributed under the terms of Article $25 \mathrm{fa}$ of the Dutch Copyright Act, indicated by the "Taverne" license above, 


\title{
Increased forefoot loading is associated with an increased plantar flexion moment
}

\author{
Tom Melai ${ }^{\mathrm{a}, \mathrm{b}}$, Nicolaas C. Schaper ${ }^{\mathrm{c}}$, T. Herman IJzerman ${ }^{\mathrm{b}}$, Ton L.H. de Lange ${ }^{\mathrm{a}}$, \\ Paul J.B. Willems ${ }^{\text {b }}$, Kenneth Meijer ${ }^{\text {b }}$, Aloysius G. Lieverse ${ }^{\mathrm{d}}$, \\ Hans H.C.M. Savelberg ${ }^{\mathrm{b}, *}$ \\ ${ }^{a}$ Department of Health Innovation \& Technology, Institute of Allied Health Professions, Fontys University of Applied \\ Sciences, Eindhoven, The Netherlands \\ ${ }^{\mathrm{b}}$ Department of Human Movement Sciences, NUTRIM School for Nutrition, Toxicology and Metabolism, Maastricht University \\ Medical Centre+, Maastricht, The Netherlands \\ ${ }^{\mathrm{c}}$ Department of Internal Medicine, CAPHRI Institute Maastricht, Maastricht University Medical Centre+, Maastricht, The Netherlands \\ ${ }^{\mathrm{d}}$ Department of Internal Medicine, Maxima Medical Centre, Eindhoven, The Netherlands
}

\section{A R T I C L E I N F O}

\section{Article history:}

Available online 16 August 2013

PsycINFO classification:

3380

Keywords:

Polyneuropathy

Diabetes

Gait analysis

Plantar pressure

Pressure time integral

Lower extremity

\begin{abstract}
A B S T R A C T
The aim of this study was to identify the cascade of effects leading from alterations in force generation around the ankle joint to increased plantar pressures under the forefoot. Gait analysis including plantar pressure measurement was performed at an individually preferred and a standardized, imposed gait velocity in diabetic subjects with polyneuropathy $(n=94)$, without polyneuropathy $(n=39)$ and healthy elderly $(n=19)$. The plantar flexion moment at $40 \%$ of the stance phase was negatively correlated with the displacement rate of center of pressure $(r=-.749, p<.001$ at the imposed, and $r=-.693, p<.001$ at the preferred gait velocity). Displacement rate of center of pressure was strongly correlated with forefoot loading $(r=-.837, p<.001$ at the imposed, and $r=-.731, p<.001$ at the preferred gait velocity). People with a relatively high plantar flexion moment at $40 \%$ of the stance phase, have a faster forward transfer of center of pressure and consequently higher loading of the forefoot. This indicates that interventions aimed at increasing the control of the roll-off of the foot may contribute to a better plantar pressure distribution.
\end{abstract}

(c) 2013 Elsevier B.V. All rights reserved.

\footnotetext{
* Corresponding author. Address: Department of Human Movement Science, Maastricht University, PO Box 616, NL-6200MD Maastricht, The Netherlands. Tel.: +31 433881392.

E-mail address: Hans.Savelberg@MaastrichtUniversity.nl (H.H.C.M. Savelberg).
} 


\section{Introduction}

Plantar foot ulceration is an invalidating co-morbidity of diabetes. Increased plantar pressure during walking is an important risk factor for (recurrent) plantar ulceration (Boulton et al., 1983) and it has been shown that the plantar pressure pattern is altered in patients with diabetes and polyneuropathy (DPN) (Allet et al., 2008; Caselli, Pham, Giurini, Armstrong, \& Veves, 2002). Several authors showed that in this population especially the forefoot is prone to higher pressures and consequently at risk for ulceration (Caselli et al., 2002; Mueller, Zou, Bohnert, Tuttle, \& Sinacore, 2008).

Diabetes has been associated with several structural and functional alterations in the foot that can result in higher plantar pressures, such as anatomical deformities (claw toes, charcot neuro-osteoarthropathy), limited joint mobility and skin changes (callus formation) (Ahroni, Boyko, \& Forsberg, 1999; Boyko et al., 1999; Bus, 2008; Morag \& Cavanagh, 1999; Morag et al., 1997; Mueller et al., 2003). Moreover, it has been suggested that changes in gait biomechanics can lead to higher loading of the foot in DPN patients (Andersen, Poulsen, Mogensen, \& Jakobsen, 1996; Savelberg, Schaper, Willems, de Lange, \& Meijer, 2009). Gait in DPN is characterized by longer stance phases, shorter steps and lower gait velocity (Kwon, Minor, Maluf, \& Mueller, 2003; Mueller, Minor, Sahrmann, Schaaf, \& Strube, 1994; Sacco \& Amadio, 2000; Savelberg et al., 2009). In this context van Deursen, Sanchez, Ulbrecht, and Cavanagh (1998) argued that deficits of the sensory nerve system could lead to alteration of gait in this population. The sensory nerve system provides information on the interaction with the ground and on the tension of the muscles. If the feedback from this system is reduced, it can lead to insecurity of gait or limitation in motor control resulting in abnormal loading of the foot (Richardson, Ching, \& Hurvitz, 1992; Sacco \& Amadio, 2000; van Deursen et al., 1998).

In addition to its effect on the sensory system, DPN can also affect the motor nervous system. Abboud, Rowley, and Newton (2000) found a delayed activation of the tibial anterior muscle, while others found prolonged activity of this muscle (Savelberg et al., 2010) or premature activation of the calf muscles in DPN (Kwon et al., 2003). Besides possible changes in muscle activation patterns, DPN affects the force generating ability. Several authors found reduced lower extremity muscle strength in people with diabetes (Andersen et al., 1996; IJzerman et al., 2011; van Schie, Vermigli, Carrington, \& Boulton, 2004). In addition, Andreassen, Jakobsen, and Andersen (2006) observed weakness of the ankle plantar and dorsiflexors in particular in DPN patients with severe neuropathy. Several authors found a combination of lower extremity muscle dysfunctioning and increased plantar pressures. They suggested that a decrease in motor control due to muscle weakness or limited feedback might be partly responsible for the observed increased plantar pressures in patients with DPN (Abboud et al., 2000; Kwon et al., 2003). In an earlier study we found higher plantar flexion moments from loading response to mid stance and an increase in plantar loading in this population (Savelberg et al., 2009). We suggested that reduced strength of the lower extremity muscles (caused by DPN) resulted in an impaired ability to brake the forward momentum of the body during the first part of the stance phase. This would have led to a faster roll-off of the foot, with a faster forward transfer of the center of pressure (COP) and consequently causing higher plantar forefoot loading. In the current study we tested the hypothesis that via the aforementioned cascade of relations, adaptations in force generation around the ankle joint result in a forwardly displaced plantar pressure pattern during gait. This hypothesis was tested in people with and without diabetes, and with and without polyneuropathy.

\section{Methods}

\subsection{Participants}

Three groups of subjects participated, with a total number of 152 (Table 1). A group of 19 healthy elderly subjects (HE, mean age of $68(S D=5)$ years) was recruited by means of advertisement or participation in previous research. Subjects with diabetes type 2 were recruited from the diabetes clinics 
Table 1

Subject characteristics.

\begin{tabular}{lcccc}
\hline Group & DPN $(n=94)$ & DC $(n=39)$ & HE $(n=19)$ & $P$-value \\
\hline Sex (male/female) & $80 / 14^{\mathrm{a}}$ & $20 / 19^{\mathrm{b}}$ & $15 / 4$ & .001 \\
Age (years) & $66.9(7.5)^{\mathrm{a}}$ & $62.4(6.6)^{\mathrm{b}}$ & $67.8(5.30$ & .002 \\
Length $(\mathrm{m})$ & $1.74(0.08)^{\mathrm{a}}$ & $1.68(0.10)$ & $1.73(0.07)$ & .002 \\
Body Mass $(\mathrm{kg})$ & $92.9(19.5)^{\mathrm{b}}$ & $88.0(15.4)^{\mathrm{b}}$ & $68.8(17.1)$ & $<.001$ \\
BMI $\left(\mathrm{kg} \mathrm{m}^{2}\right)$ & $30.5(5.6)^{\mathrm{b}}$ & $31.1(5.7)^{\mathrm{b}}$ & $23.2(5.6)$ & $<.001$ \\
CNE score & $12.9(5.2)^{\mathrm{ab}}$ & $2.5(1.6)^{\mathrm{b}}$ & $1.4(1.5)$ & $<.001$ \\
HbA1c $(\%)$ & $7.3(1.1)^{\mathrm{b}}$ & $7.1(1.0)^{\mathrm{b}}$ & $6.0(0.5)$ & $<.001$ \\
Glucose $(\mathrm{mmol} / \mathrm{L})$ & $8.5(2.4)^{\mathrm{b}}$ & $8.0(2.2)^{\mathrm{b}}$ & $5.6(0.6)$ & $<.001$ \\
Creatinin $(\mu \mathrm{mol} / \mathrm{L})$ & $98.3(30.0)^{\mathrm{a}}$ & $81.2(22.2)$ & $89.0(12.4)$ & .003 \\
\hline
\end{tabular}

Data are presented for the subjects included in the study as mean $(S D)$. Abbreviations: DPN: Diabetic polyneuropathy; DC: Diabetic Control; HE: Healthy Elderly; CNE: Clinical Neurological Examination. The P-values show overall group differences for each variable. a Differs significantly from DC, and b differs significantly from HE, based on post hoc analysis.

of 3 general and 1 academic hospital in the Netherlands. All participants underwent a standardized Clinical Neurological Examination (CNE) to determine the level of DPN. The CNE included reflexes, vital and gnostic sensibility and lower extremity muscle strength (Valk et al., 1997). Based on this validated scoring system 94 patients $(67(S D=8)$ years) were diagnosed with DPN and 39 diabetic controls did not have clinical signs of polyneuropathy ( $D C, 62(S D=7)$ years). All subjects were above 50 years of age and were able to walk 6 minutes without walking aids. Subjects were excluded if diagnosed with severe cardiac disease, renal dysfunction (creatinin $>180 \mu \mathrm{mol} / \mathrm{l}$ ), intermittent claudication, neurological disorders other than DPN, rheumatoid arthritis, severe osteoarthritis, major foot deformities or amputations, or prior or current foot ulceration. All participants signed an informed consent; the protocol was approved by the medical ethical committee of Maastricht University Medical Centre+.

\subsection{Experimental set-up}

Subjects were tested in the gait laboratories of two institutes in the southern part of the Netherlands. For gait analysis at the first institute a wooden walkway was available with embedded a pressure platform (EMED-x, $100 \mathrm{~Hz}, 4$ sensors $/ \mathrm{cm}^{2}$, range $0-127 \mathrm{~N} / \mathrm{cm}^{2}$, Novel Inc., Munich, Germany) mounted on top of the force platform (AMTI LG6_2-1, Advanced Medical Technology Inc, Newton, MA, US). At the second institute a similar set up was present, with a comparable force and pressure platform (force platform: Kistler 9281A SN, Kistler instrumente AG, Winterhur Switzerland; pressure platform: $50 \mathrm{~Hz}, 2$ sensors $/ \mathrm{cm}^{2}$, range $0-120 \mathrm{~N} / \mathrm{cm}^{2}$, Novel Inc., Munich, Germany). At both sites a digital high speed camera (1.3 megapixel Pixellink PL-A741, sampling at $100 \mathrm{~Hz}$ ) was used to assess 2D kinematic data in the sagital plane. Participants were equipped with reflective markers attached to the skin at the middle of the greater trochanter, lateral femoral epicondyle, calcaneus, lateral malleolus and fifth metatarsal of the right leg. Gait velocity was determined by means of the horizontal displacement of the marker on the greater trochanter during one stride over the force plate. To determine spatiotemporal gait characteristics a tri-axial accelerometer was attached to the subjects' sacrum by means of double layered tape.

\subsection{Study protocol}

All subjects wore shorts, walked barefoot and were allowed to familiarize themselves with the test settings. Measurements were performed at two gait velocities. At first the subjects were asked to complete 5 successful trials over the test track at their own preferred gait velocity. A trial was successful if the subject stepped on the platform with their right foot without aiming. As gait velocity affects plantar loading (Segal et al., 2004) and subjects with diabetes and polyneuropathy walk slower (Savelberg et al., 2010), all subjects were asked to complete 5 trails at a standardized, imposed gait velocity of 


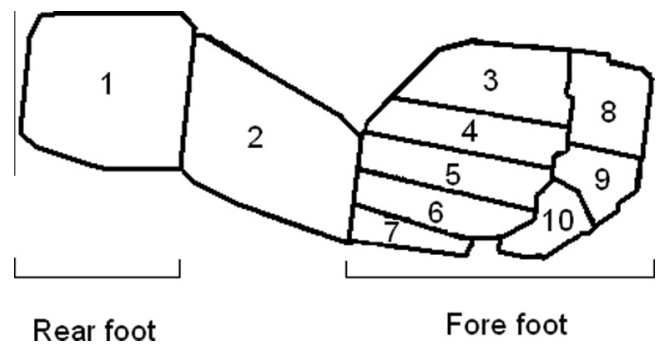

Fig. 1. Mask division of plantar areas with indication of the areas used to calculate forefoot to rear foot ratio. Area $1=$ heel, area $2=$ mid foot, areas 3-7 = metatarsal regions, area $8=$ hallux, areas 9 and $10=$ smaller toes.

$1.2 \mathrm{~m} / \mathrm{s}$, with a maximal deviation of 0.1 . This range resembles the preferred gait velocity for this age group (Savelberg et al., 2010). Using an even smaller range would demand too many repetitions to reach 5 successful trials and would be too exhausting for the subjects.

\subsection{Analysis}

Plantar pressure data were masked in Novel Database Medical (13.3.42, Germany 2007) using the Novel 10 mask division (see Fig. 1). Trials were excluded if inconsistencies occurred in the automatic masking procedure, for example due to dragging of the hallux over the pressure platform. For each trial an ASCII output was generated that included the peak pressure (PP), the force time integral and the contact area per foot region. Using Matlab (R2007b, USA 2007), the PTI was calculated as the quotient of the force time integral and contact area for each mask (Melai et al., 2011). The forefoot to rear foot ratio (F/R-ratio) was calculated by taking the quotient of the PTI of the forefoot (areas 310, see Fig. 1) and the heel (area1). The velocity of forward transfer of the COP (tCOP) was expressed as the percentage of the stance phase needed for the COP to reach the forefoot (area 3-10). Internal joint moments were obtained by means of inverse dynamics as applied in Savelberg et al. (Savelberg et al., 2009). All joint moments were normalized for body mass. This included the maximal hip flexion and extension (H-flex, H-ext) and maximal knee flexion and extension moment (K-flex, K-ext), as well as the maximal, plantar flexion ankle joint moment (A-plant) and the plantar flexion ankle joint moments at $40 \%$ of the stance phase (A-40). This value of $40 \%$ was chosen based on earlier research, that indicated that at this time point the ankle joint moment showed the largest differences between people with and without DPN (Savelberg et al., 2009). Based on this research, the A-40 and A-plant were used in a quotient to characterize the ankle joint moment pattern in one value (A-40/ A-plant).

The duration of the stance phase was determined as the time the right foot was in contact with the force platform. Stride length and stride duration were determined by assessing the duration of two successive peaks of the vertical acceleration signal and the average forward velocity (determined by the marker on the greater trochanter).

Averages for all variables were determined per subject based on a minimum of three correct trials.

\subsection{Statistical analysis}

All data were analyzed using SPSS 15.0 for Windows. For both gait velocities separately, correlations between the A-40/A-plant, tCOP and F/R-ratio were determined using Pearson's correlation coefficient for all group together; these respective correlations were considered the main outcome of this study. Differences between groups were determined using a one way analysis of variance. Due to unequal variances in the different groups the Games-Howell test was used for post hoc analysis. Differences were considered significant if $p \leqslant .05$. 


\section{Results}

Twenty-four subjects (21 DPN, 3 DC) were not able to reach the imposed gait velocity due to their health status. Hence, only their preferred gait velocity could be analyzed. Due to technical problems or incorrect loading of one of the platforms data were obtained in 117 subjects ( 72 DPN, 28 DC, $17 \mathrm{HE}$ ) at the preferred gait velocity, and 91 subjects (56 DPN, 29 DC, $16 \mathrm{HE}$ ) at for the imposed gait velocity.

\subsection{Correlations between pressure characteristics and joint moments}

For the primary outcome measure all groups were analyzed together. Forwardly shifted foot pressures (F/R-ratio) correlated to higher displacement rate of COP (imposed gait velocity:

A

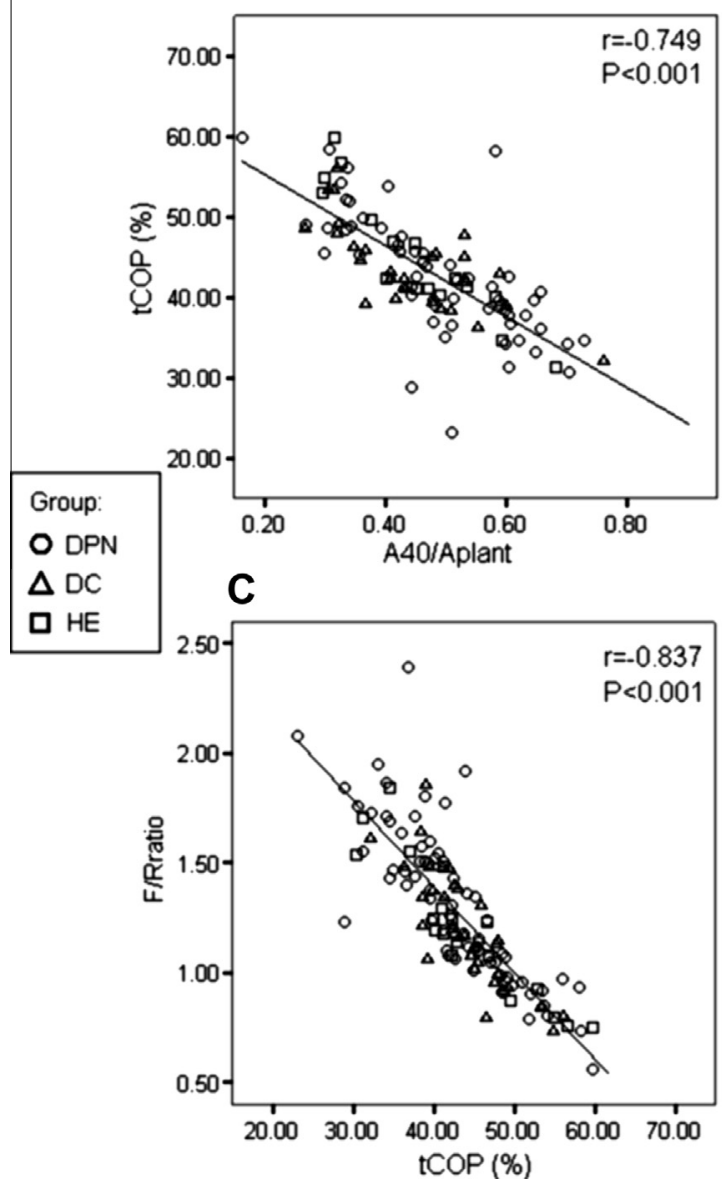

B
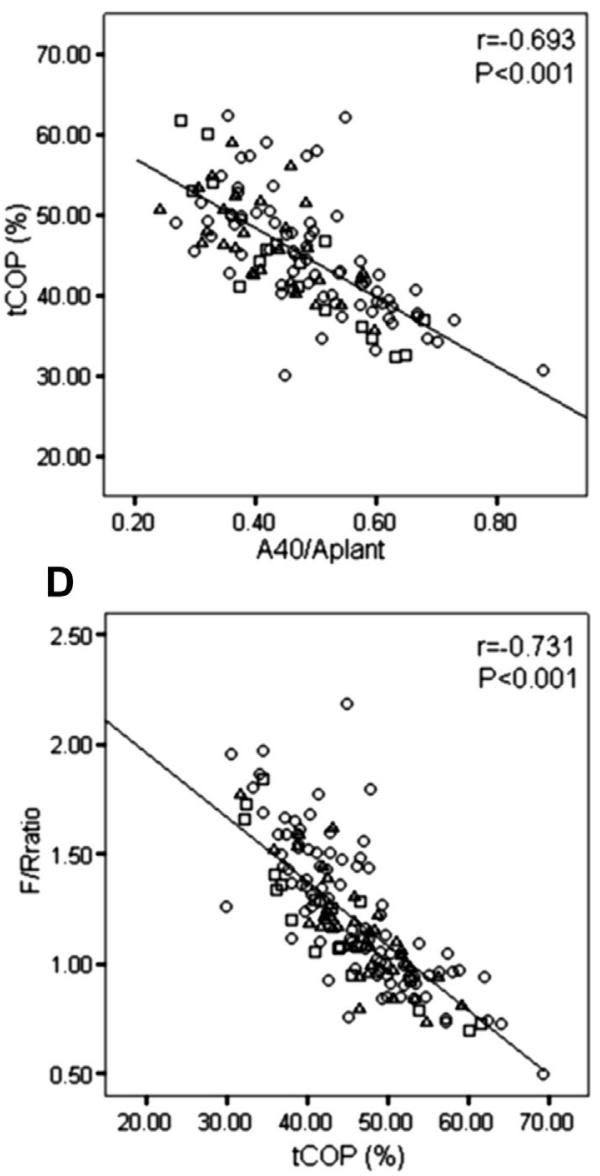

Fig. 2. A and B: Correlation of characterization of ankle joint moment (A-40/A-plant) and displacement rate of center of pressure (tCOP) for the imposed (1A) and preferred gait velocity (1B). A higher relative ankle joint moment at $40 \%$ of the stance phase is correlated with a faster forward transfer of the COP. C and D: Correlation of tCOP and the forefoot to rear foot PTI ratio (F/R ratio) for the imposed (1C) and preferred gait velocity (1D). A faster forward transfer of the COP results in a relatively earlier loading of the forefoot which is correlated with higher loading of the forefoot. Abbreviations: A-40: Ankle plantar flexion joint moment at $40 \%$ of the stance phase; A-plant: Maximal plantar flexion ankle joint moment; tCOP: percentage of stance duration the centre of pressure needs to reach the forefoot. F/R ratio: quotient of the pressure time integral (PTI) under the forefoot and rear foot. 
Table 2

Means and standard errors of gait characteristics, internal joint moments, three main variables (A-40/A-plant, tCOP and F/R ratio) and plantar pressures (PP and PTI per foot region).

\begin{tabular}{|c|c|c|c|c|c|c|c|c|}
\hline & \multicolumn{4}{|l|}{ Preferred } & \multicolumn{4}{|l|}{ Imposed } \\
\hline & DPN & DC & $\mathrm{HE}$ & $P$ & DPN & DC & $\mathrm{HE}$ & $P$ \\
\hline Gait velocity (m/s) & $1.07(.02)^{b}$ & $1.09(.04)^{b}$ & $1.22(.04)$ & .006 & $1.23(.04)$ & $1.23(.06)$ & $1.23(.04)$ & .925 \\
\hline Stride duration (s) & $1.15(.01)$ & $1.13(.02)$ & $1.09(.02)$ & .061 & $1.04(.07)$ & $1.04(.08)$ & $1.07(.08)$ & .401 \\
\hline Stride length (m) & $1.26(01)^{\mathrm{a}}$ & $1.22(.03)$ & $1.33(.03)$ & .045 & $1.28(.01)$ & $1.28(.02)$ & $1.31(.02)$ & .479 \\
\hline Stance phase duration (s) & $.73(.01)^{\mathrm{b}}$ & $.72(.01)$ & $.67(.02)$ & .017 & $.65(.05)$ & $.64(.05)$ & $.66(.05)$ & .664 \\
\hline H-ext (Nm/kg) & $.66(.03)$ & $.62(.05)$ & $.79(.07)$ & .131 & $.74(.03)$ & $.65(.05)$ & $.74(.06)$ & .125 \\
\hline H-flex (Nm/kg) & $.51(.03)$ & $.42(.05)$ & $.57(.07)$ & .163 & $.63(.03)$ & $.53(.05)$ & $.56(.06)$ & .770 \\
\hline K-ext $(\mathrm{Nm} / \mathrm{kg})$ & $.19(.03)$ & $.13(.02)$ & $.24(.04)$ & .210 & $.20(.03)$ & $.12(.02)$ & $.23(.04)$ & .678 \\
\hline K-flex $(\mathrm{Nm} / \mathrm{kg})$ & $.43(.02)$ & $.48(.04)$ & $.52(.06)$ & .224 & $.53(.03)$ & $.57(.03)$ & $.54(.04)$ & .053 \\
\hline A-plant (Nm/kg) & $1.54(.02)$ & $1.55(.04)$ & $1.59(.04)$ & .529 & $1.57(.02)$ & $1.55(.04)$ & $1.58(.04)$ & .237 \\
\hline $\mathrm{A}-40(\mathrm{Nm} / \mathrm{kg})$ & $.76(.02)^{\mathrm{a}}$ & $.65(.02)$ & $.74(.05)$ & .019 & $.75(.03)$ & $.67(.02)$ & $.71(.05)$ & .179 \\
\hline A-40/A-plant & $.49(.01)^{\mathrm{a}}$ & $.42(.02)$ & $.47(.03)$ & .021 & $.48(.02)$ & $.45(.02)$ & $.45(.03)$ & .292 \\
\hline $\mathrm{COP}(\%)$ & $46.0(.80)$ & $45.5(1.36)$ & $43.5(1.98)$ & .480 & $42.7(.89)$ & $44.3(.93)$ & $43.8(1.88)$ & .519 \\
\hline $\mathrm{F} / \mathrm{R}$ ratio & $1.24(.03)$ & $1.17(.04)$ & $1.20(.07)$ & .490 & $1.31(.04)$ & $1.20(.05)$ & $1.21(.07)$ & .222 \\
\hline PP Heel $\left(\mathrm{N} / \mathrm{cm}^{2}\right)$ & $38.1(1.1)$ & $36.0(1.6)$ & $36.0(2.6)$ & .517 & $42.9(1.4)$ & 40.5 (1.9) & $36.9(2.3)$ & .126 \\
\hline PP Midfoot $\left(\mathrm{N} / \mathrm{cm}^{2}\right)$ & $15.4^{\mathrm{b}}(.6)$ & $15.6^{\mathrm{b}}(.8)$ & $12.0(.7)$ & .028 & $15.9(.7)^{\mathrm{b}}$ & $15.6(.8)^{\mathrm{b}}$ & $12.0(.5)$ & .023 \\
\hline PP MT1 $\left(\mathrm{N} / \mathrm{cm}^{2}\right)$ & $43.2^{\mathrm{b}}(2.5)$ & $36.2(3.8)$ & $28.2(2.2)$ & .021 & $44.5(2.8)^{\mathrm{ab}}$ & $32.1(2.7)$ & $28.1(2.5)$ & .001 \\
\hline PP MT2 $\left(\mathrm{N} / \mathrm{cm}^{2}\right)$ & $57.1(2.6)$ & $47.1(3.8)$ & $45.9(4.4)$ & .039 & $60.7(3.0)^{\mathrm{b}}$ & $51.6(4.2)$ & $46.1(5.0)$ & .036 \\
\hline PP MT3 $\left(\mathrm{N} / \mathrm{cm}^{2}\right)$ & $46.9^{\mathrm{b}}(1.8)$ & $40.9(2.5)$ & $36.4(1.5)$ & .011 & $49.0(2.3)^{\mathrm{b}}$ & $44.8(3.1)^{\mathrm{b}}$ & $35.7(1.7)$ & .014 \\
\hline PP MT4 $\left(\mathrm{N} / \mathrm{cm}^{2}\right)$ & $31.3^{\mathrm{b}}(1.2)$ & $27.5(1.2)$ & $24.2(1.0)$ & .007 & $31.5(1.7)^{b}$ & $28.5(1.2)$ & $25.3(1.7)$ & .101 \\
\hline PP MT5 (N/cm²) & $31.2^{\mathrm{ab}}(2.2)$ & $22.8(2.1)$ & $20.0(2.5)$ & .009 & $29.1(2.3)$ & $22.6(2.0)$ & $23.9(4.1)$ & .160 \\
\hline PP Hallux $\left(\mathrm{N} / \mathrm{cm}^{2}\right)$ & $44.4^{\mathrm{b}}(2.6)$ & $45.8(4.5)$ & $33.6(2.6)$ & .178 & $45.0(3.0)^{b}$ & $49.6(5.0)^{b}$ & $34.1(3.4)$ & .099 \\
\hline PP Dig $2\left(\mathrm{~N} / \mathrm{cm}^{2}\right)$ & $20.6(1.4)$ & $19.3(1.7)$ & $20.9(2.1)$ & .824 & $21.4(1.5)$ & $20.6(1.8)$ & $20.7(2.3)$ & .932 \\
\hline PP Dig 3-5 $\left(\mathrm{N} / \mathrm{cm}^{2}\right)$ & $14.1(.9)$ & $13.9(1.2)$ & $15.4(1.7)$ & .799 & $13.8(.8)$ & $15.94(1.6)$ & $15.2(1.8)$ & .405 \\
\hline PTI Heel $\left(\mathrm{Ns} / \mathrm{cm}^{2}\right)$ & $4.17(.13)^{\mathrm{b}}$ & $4.02(.15)^{\mathrm{b}}$ & $3.23(.19)$ & .004 & $3.47(.10)$ & $3.45(.11)$ & $3.12(.15)$ & .233 \\
\hline PTI Midfoot (Ns/ $\mathrm{cm}^{2}$ ) & $1.69(.09)^{b}$ & $1.86(.14)^{b}$ & $.96(.09)$ & .001 & $1.35^{\mathrm{b}}(.08)$ & $1.47(.10)^{\mathrm{b}}$ & $1.00(.08)$ & .032 \\
\hline PTI MT1 (Ns/cm $\left.{ }^{2}\right)$ & $5.18(.20)^{\mathrm{b}}$ & $4.77(.24)^{\mathrm{b}}$ & $3.45(.25)$ & $<.001$ & $4.76(.22)^{\mathrm{ab}}$ & $4.02(.19)$ & $3.30(.26)$ & .001 \\
\hline PTI MT2 (Ns/cm²) & $7.18(.19)^{\mathrm{b}}$ & $6.55(.21)^{\mathrm{b}}$ & $5.52(.31)$ & $<.001$ & $6.49(.20)^{\mathrm{b}}$ & $5.99(.22)$ & $5.38(.28)$ & .015 \\
\hline PTI MT3 (Ns/cm²) & $6.59(.17)^{\mathrm{b}}$ & $6.38(.24)^{b}$ & $5.15(.24)$ & .001 & $5.83(.16)^{b}$ & $5.75(.23)$ & $5.05(.22)$ & .071 \\
\hline PTI MT4 (Ns/cm²) & $5.28(.17)^{\mathrm{b}}$ & $5.30(.25)^{\mathrm{b}}$ & $4.07(.25)$ & .007 & $4.49(.14)$ & $4.65(.22)$ & $4.12(.30)$ & .334 \\
\hline PTI MT5 (Ns/cm²) & $4.11(.20)^{b}$ & $3.78(.22)$ & $2.89(.30)$ & .023 & $3.29(.16)$ & $3.25(.19)$ & $3.07(.37)$ & .819 \\
\hline PTI Hallux $\left(\mathrm{Ns} / \mathrm{cm}^{2}\right)$ & $2.89(.13)$ & $2.90(.18)$ & $2.59(.17)$ & .577 & $2.59(.13)$ & $2.68(.18)$ & $2.52(.25)$ & .859 \\
\hline PTI Dig $2\left(\mathrm{Ns} / \mathrm{cm}^{2}\right)$ & $1.80(.10)$ & $1.66(.11)$ & $1.78(.17)$ & .675 & $1.57(.09)$ & $1.52(.12)$ & $1.80(.22)$ & .426 \\
\hline PTI Dig 3-5 (Ns/cm²) & $1.16(.07)$ & $1.21(.11)$ & $1.32(.17)$ & .626 & $.97(.07)$ & $1.06(.10)$ & $1.26(.17)$ & .178 \\
\hline
\end{tabular}

Differences based on post hoc testing: a differs significantly from DC, b differs significantly from HE.

All joint moments are corrected for body mass. Abbreviations: H-ext: Maximum hip extension moment; H-flex: maximum hip flexion moment; K-ext: Maximum knee extension moment; A-plant: maximum plantar flexion moment; A-40: plantar flexion joint moment at $40 \%$ of the stance phase; tCOP: the percentage of the stance phase needed for the centre of pressure to reach the forefoot; PP: peak pressure; PTI: Pressure Time Integral; MT: metatarsal heads; Dig: digitorum; F/R ratio: Forefoot to rear foot PTI ratio.

$r=-.837, p<.001$; preferred gait velocity: $r=-.731, p<.001)$. The displacement rate of the COP (tCOP) correlated with the relative plantar flexor moment (A-40/A-plant) of the first half of the stance phase (imposed gait velocity: $r=-.749, p<.001$; preferred gait velocity: $r=-.693, p<.001$, Fig 2).

\subsection{Plantar pressure}

For the preferred gait velocity, DPN patients showed higher plantar loading in all areas under mid and forefoot in terms of PP and PTI than those in the HE group. At the imposed gait velocity the pressures (PTI and PP) under the mid foot and first and second metatarsal heads were significantly increased in DPN patients (Table 2). In contrast to this increase of absolute loading in the forefoot, the data showed no differences between groups in displacement of COP or F/R-ratio. 


\subsection{Joint moments}

For the preferred gait velocity, the post hoc analysis showed significantly higher values for A-40 and A-40/A-plant for DPN compared to DC ( $p=.003$ and $p=.007$, respectively, Table 2$)$. No group differences were found in joint moments for the imposed velocity.

\subsection{Spatiotemporal gait characteristics}

Both DPN and DC patients preferred to walk slower than the healthy control subjects $(p=.006$, Table 2). In addition, during the preferred gait velocity, the DPN group tended to have a longer stride duration than the HE group ( $p=.061)$. Also in the DPN group the relative duration of stance phase was longer $(p=.008)$ and subjects in this group took shorter strides than HE participants $(p=.017)$. These differences were not present during the imposed gait velocity.

\section{Discussion}

The aim of this study was to test the hypothesis that adaptations in force generation around the ankle joint result, via a cascade of relations, in a forwardly displaced plantar pressure pattern during gait. We observed that, irrespective of gait velocity, subjects who had a high A-40/A-plant had a faster forward transfer of the COP and showed simultaneously increased forefoot loading, as shown in Fig. 2. This supports the hypothesis that the inability to generate enough force to brake the forward velocity during the first half of the stance phase contributes to a shift of pressure towards the forefoot. To the best of our knowledge, current study is the first to explicitly associate the force generating capacity by extrinsic muscles to plantar pressure patterns. This finding suggests that muscle weakness, a limited rate of force development, or delayed muscle activation contributes to adverse forefoot loading. It is possible that diminished functioning of the tibial anterior muscle causes a diminished control of the roll-off of the foot during loading response, resulting in a faster forward progression of the COP. Also the plantar flexors are involved in braking the forward progression of COP, as these muscles eccentrically brake the forward progression of tibia during mid-stance. However, we observed in a previous study (Savelberg et al., 2009) that people with DPN have no apparent problem controlling the plantar flexion moment during the second half of stance phase, during which the role of the plantar flexors is more prominent. Future research needs to further clarify the contribution of the lower limb muscles to plantar pressures in DPN. Nevertheless, high plantar pressures are currently regarded as a local problem, and treated with shoe and offloading technology, but based on the results of the current study also other treatment options, such as training muscle strength or coordination, can be explored.

Based on previous literature, (IJzerman et al., 2011; van Schie et al., 2004) it was expected that patients with DPN would have reduced muscle strength and thus would more frequently have a higher plantar flexion moment in early stance phase, limited braking capacity, a faster forward displacement of COP and higher loading of the forefoot (Savelberg et al., 2009). In the current study the DPN patients did not show this outcome for the imposed gait velocity. The preferred gait velocity showed a higher A-40/A-plant for DPN patients compared to DC, but no increase in displacement of COP or forefoot loading. We did observe the cascade that connects ankle joints moments and loading of the forefoot in both diabetic groups, with and without DPN, and healthy subjects. This indicates that interventions aimed at increasing the control of the roll-off of the foot (e.g., training muscle strength or coordination) may contribute to the prevention of adverse plantar pressures patterns, even for people that are not at a direct risk for ulceration.

In the current study we observed group differences for spatiotemporal gait characteristics, plantar pressures and gait dynamics, which could have affected previously described cascade of relations.

The spatiotemporal gait characteristics of the current population showed that under the preferred gait velocity, people with DPN increased their stance phase duration and shorten their stride lengths. This finding is in concordance with previous observations. At preferred gait velocity Sawacha et al. Sawacha et al. (2009) found increased stance phases and shorter stride lengths for people with 
diabetes, irrespective of the presence of polyneuropathy. Savelberg et al. (2010) tested these same groups but did not observe any differences in spatiotemporal variables between groups; in addition they reported an influence of gait velocity on stride duration and stride length. This could mean that the longer stance phase duration and shorter stride lengths that were observed in the present study resulted from the lower gait velocity of participants with diabetes. The study of Sawacha et al. (Sawacha et al., 2009) showed indeed that people with diabetes walk slower than healthy subjects, again irrespective of the presence of polyneuropathy. The current study showed that when people with DPN where asked to walk at the same gait velocity as people without diabetes, the differences in gait characteristics disappeared. It is therefore assumed that the reported shorter stride length and longer stance phase duration found for people with diabetes and polyneuropathy are due to a lower, preferred gait velocity.

Significantly higher absolute loading, in terms of both PP and PTI, was found in the plantar forefoot of DPN patients. However, a forward shift of pressures could not be held responsible for this, as F/Rratio and tCOP did not differ between groups. It is possible that increased absolute loading is due to structural and functional alterations as described by several authors (Ahroni et al., 1999; Boyko et al., 1999; Bus, 2008; Morag \& Cavanagh, 1999; Morag et al., 1997; Mueller et al., 2003). Body mass is another factor that could lead to higher loading of the foot and therefore higher plantar pressures (Hills, Hennig, McDonald, \& Bar-Or, 2001; Vela, Lavery, Armstrong, \& Anaim, 1998). As the DPN group was significantly heavier than the other two groups, this will have led to differences in plantar pressures as well.

Regarding gait dynamics, our data showed an increased plantar flexion moment at $40 \%$ of the stance phase for people with DPN walking at their preferred gait velocity. Other joint moment variables, including the maximal plantar flexion, did not differ significantly over the groups. These findings conflict with the outcome of two earlier small studies. At preferred gait velocity, Mueller et al. (1994) and Kwon et al. (2003) found a decrease in plantar flexion joint moments for people with DPN with respect to HE. Apart from the higher statistical power of the present study relative to these earlier studies (117 versus 10 and 9 respectively) we were not able to explain these differences in outcome.

It should be noted that the current study has some limitations. The subject groups were based on a convenience sample and not matched or balanced, which might have influenced group differences. This possible bias was at least partly circumvented by the application of quotients for our main outcome variables on plantar pressure and joint moments. Even more, the correlation analysis was performed with all groups together, eliminating any possible bias in group characteristics.

In addition, for our inverse dynamic calculation no 3D kinematics were available. However a previous study indicated that the application of 2D kinematics is appropriate when analyzing human gait in the sagittal plain (Alkjaer, Simonsen, \& Dyhre-Poulsen, 2001).

\section{Conclusion}

This study showed that a forward shift of plantar pressure is associated with a faster forward transfer of the COP, which is associated to a high, internal plantar flexion moment at 40 percent of the stance phase. It shows that force generation around the ankle joint plays an important role in the development of higher plantar pressures of the forefoot. Therefore it is to be expected that an intervention aimed at increasing the force generating abilities of the lower extremity can contribute to offloading of the forefoot.

\section{Acknowledgments}

We would like to acknowledge the Dutch Diabetes Federation and ZonMw for project funding. In addition we would like to acknowledge the contribution of P. Hermkes MSc., A. Toorians PhD. MD. and H. van Vroenhoven in recruitment and data-acquisition. 


\section{References}

Abboud, R. J., Rowley, D. I., \& Newton, R. W. (2000). Lower limb muscle dysfunction may contribute to foot ulceration in diabetic patients. Clinical Biomechanics (Bristol, Avon), 15, 37-45.

Ahroni, J. H., Boyko, E. J., \& Forsberg, R. C. (1999). Clinical correlates of plantar pressure among diabetic veterans. Diabetes Care, $22,965-972$.

Alkjaer, T., Simonsen, E. B., \& Dyhre-Poulsen, P. (2001). Comparison of inverse dynamics calculated by two- and threedimensional models during walking. Gait \& Posture, 13, 73-77.

Allet, L., Armand, S., Golay, A., Monnin, D., de Bie, R. A., \& de Bruin, E. D. (2008). Gait characteristics of diabetic patients: A systematic review. Diabetes/Metabolism Research and Reviews, 24, 173-191.

Andersen, H., Poulsen, P. L., Mogensen, C. E., \& Jakobsen, J. (1996). Isokinetic muscle strength in long-term IDDM patients in relation to diabetic complications. Diabetes, 45, 440-445.

Andreassen, C. S., Jakobsen, J., \& Andersen, H. (2006). Muscle weakness: A progressive late complication in diabetic distal symmetric polyneuropathy. Diabetes, $55,806-812$.

Boulton, A. J., Hardisty, C. A., Betts, R. P., Franks, C. I., Worth, R. C., Ward, J. D., et al (1983). Dynamic foot pressure and other studies as diagnostic and management aids in diabetic neuropathy. Diabetes Care, 6, 26-33.

Boyko, E. J., Ahroni, J. H., Stensel, V., Forsberg, R. C., Davignon, D. R., \& Smith, D. G. (1999). A prospective study of risk factors for diabetic foot ulcer. The Seattle Diabetic Foot Study. Diabetes Care, 22, 1036-1042.

Bus, S. A. (2008). Foot structure and footwear prescription in diabetes mellitus. Diabetes/Metabolism Research and Reviews, 24(Suppl. 1), S90-95.

Caselli, A., Pham, H., Giurini, J. M., Armstrong, D. G., \& Veves, A. (2002). The forefoot-to-rearfoot plantar pressure ratio is increased in severe diabetic neuropathy and can predict foot ulceration. Diabetes Care, 25, 1066-1071.

Hills, A. P., Hennig, E. M., McDonald, M., \& Bar-Or, O. (2001). Plantar pressure differences between obese and non-obese adults: A biomechanical analysis. International Journal of Obesity Related Metabolic Disorders, 25, 1674-1679.

IJzerman, T. H., Schaper, N. C., Melai, T., Blijham, P., Meijer, K., Willems, P. J., et al (2011). Motor nerve decline does not underlie muscle weakness in type 2 diabetic neuropathy. Muscle Nerve, 44, 241-245.

Kwon, O. Y., Minor, S. D., Maluf, K. S., \& Mueller, M. J. (2003). Comparison of muscle activity during walking in subjects with and without diabetic neuropathy. Gait $\mathcal{E}$ Posture, 18, 105-113.

Melai, T., Ijzerman, T. H., Schaper, N. C., de Lange, T. L., Willems, P. J., Meijer, K., et al (2011). Calculation of plantar pressure time integral, an alternative approach. Gait \& Posture, 34, 379-383.

Morag, E., \& Cavanagh, P. R. (1999). Structural and functional predictors of regional peak pressures under the foot during walking. Journal of Biomechanics, 32, 359-370.

Morag, E., Pammer, S., Boulton, A., Young, M., Deffner, K., \& Cavanagh, P. (1997). Structural and functional aspects of the diabetic foot. Clinical Biomechanics (Bristol, Avon), 12, S9-S10.

Mueller, M. J., Minor, S. D., Sahrmann, S. A., Schaaf, J. A., \& Strube, M. J. (1994). Differences in the gait characteristics of patients with diabetes and peripheral neuropathy compared with age-matched controls. Physical Therapy, 74, 299-308. discussion 309-213.

Mueller, M. J., Hastings, M., Commean, P. K., Smith, K. E., Pilgram, T. K., Robertson, D., et al (2003). Forefoot structural predictors of plantar pressures during walking in people with diabetes and peripheral neuropathy. Journal of Biomechanics, 36, 1009-1017.

Mueller, M. J., Zou, D., Bohnert, K. L., Tuttle, L. J., \& Sinacore, D. R. (2008). Plantar stresses on the neuropathic foot during barefoot walking. Physical Therapy, 88, 1375-1384.

Richardson, J. K., Ching, C., \& Hurvitz, E. A. (1992). The relationship between electromyographically documented peripheral neuropathy and falls. Journal of the American Geriatrics Society, 40, 1008-1012.

Sacco, I. C., \& Amadio, A. C. (2000). A study of biomechanical parameters in gait analysis and sensitive cronaxie of diabetic neuropathic patients. Clinical Biomechanics (Bristol, Avon), 15, 196-202.

Savelberg, H. H., Ilgin, D., Angin, S., Willems, P. J., Schaper, N. C., \& Meijer, K. (2010). Prolonged activity of knee extensors and dorsal flexors is associated with adaptations in gait in diabetes and diabetic polyneuropathy. Clinical Biomechanics (Bristol, Avon), 25, 468-475.

Savelberg, H. H., Schaper, N. C., Willems, P. J., de Lange, T. L., \& Meijer, K. (2009). Redistribution of joint moments is associated with changed plantar pressure in diabetic polyneuropathy. BMC Musculoskelet Disorders, 10, 16.

Sawacha, Z., Gabriella, G., Cristoferi, G., Guiotto, A., Avogaro, A., \& Cobelli, C. (2009). Diabetic gait and posture abnormalities: A biomechanical investigation through three dimensional gait analysis. Clinical Biomechanics (Bristol, Avon), 24, $722-728$.

Segal, A., Rohr, E., Orendurff, M., Shofer, J., O’Brien, M., \& Sangeorzan, B. (2004). The effect of walking speed on peak plantar pressure. Foot \& Ankle International, 25, 926-933.

Valk, G. D., de Sonnaville, J. J., van Houtum, W. H., Heine, R. J., van Eijk, J. T., Bouter, L. M., et al (1997). The assessment of diabetic polyneuropathy in daily clinical practice: Reproducibility and validity of Semmes Weinstein monofilaments examination and clinical neurological examination. Muscle Nerve, 20, 116-118.

van Deursen, R. W., Sanchez, M. M., Ulbrecht, J. S., \& Cavanagh, P. R. (1998). The role of muscle spindles in ankle movement perception in human subjects with diabetic neuropathy. Experimental Brain Research, 120, 1-8.

van Schie, C. H., Vermigli, C., Carrington, A. L., \& Boulton, A. (2004). Muscle weakness and foot deformities in diabetes: Relationship to neuropathy and foot ulceration in caucasian diabetic men. Diabetes Care, 27, 1668-1673.

Vela, S. A., Lavery, L. A., Armstrong, D. G., \& Anaim, A. A. (1998). The effect of increased weight on peak pressures: Implications for obesity and diabetic foot pathology. Journal of Foot and Ankle Surgery, 37, 416-420. discussion 448-419. 